\title{
Total hip arthroplasty for tuberculosis: a case series
}

\author{
Jin Zhang ${ }^{1 \#}$, Liang Liang ${ }^{1 \#}$, Bo Yang ${ }^{2}$, Senlei $\mathrm{Li}^{1}$, Xianteng Yang ${ }^{1}$, Jianyang Li $^{1}$, Li Sun ${ }^{1}$, Wei Han ${ }^{1}$ \\ ${ }^{1}$ Department of Orthopaedics, Guizhou Provincial People's Hospital, Guiyang, China; ${ }^{2}$ Department of Orthopaedics, Kaili City First People's \\ Hospital, Kaili, China \\ Contributions: (I) Conception and design: J Zhang, L Liang, L Sun, W Han; (II) Administrative support: L Sun, W Han; (III) Provision of study \\ materials or patients: J Zhang, B Yang, S Li; (IV) Collection and assembly of data: J Zhang, B Yang, S Li; (V) Data analysis and interpretation: J \\ Zhang, X Yang, J Li; (VI) Manuscript writing: All authors; (VII) Final approval of manuscript: All authors. \\ \#These authors contributed equally to this work. \\ Correspondence to: Li Sun, MD; Wei Han. Department of Orthopaedics, Guizhou Provincial People's Hospital, Guiyang, Guizhou province, China. \\ Address: 83 Zhongshan East Road, Guiyang 550002, China. Email: 1060561853@qq.com; 1796981413@qq.com.
}

\begin{abstract}
Background: The purpose of this study is to investigate the optimal surgical options for different kinds of advanced hip tuberculosis, which are still controversial.

Methods: We reviewed seven advanced hip tuberculosis patients received operations from November 2014 to September 2018. All patients received anti-tubercular chemotherapy at least 2 weeks preoperatively and twelve months postoperatively. One active case with sinus tract of seven patients underwent three-stage operations including two debridements/cement spacer implantations and one total hip arthroplasty, while the other six cases received one $=$ stage arthroplasty surgery. All patients are followed up based on Harris score, C-reactive protein (CRP), erythrocyte sedimentation rate (ESR) and X-ray.
\end{abstract}

Results: The mean follow-up time was 41.6 months, while no reactivation was detected. The average Harris score increased from 40.0 preoperatively to 89.4 at the final follow-up. ESR of 3 active hip tubercular cases decreased from $143.7 \mathrm{~mm} / \mathrm{L}$ at diagnosis time to $6.7 \mathrm{~mm} / \mathrm{L}$ at the final follow-up. CRP of 3 active hip tubercular cases decreased from $80.01 \mathrm{mg} / \mathrm{L}$ (range, $37.34-136.92 \mathrm{mg} / \mathrm{L}$ ) at diagnosis time to $1.91 \mathrm{mg} / \mathrm{L}$ (range, $1.05-2.57 \mathrm{mg} / \mathrm{L}$ ) at the final follow-up. The ESR and CRP of all patients had returned to normal level at the final follow-up. No prosthesis dislocation, loosening and neurovascular injury was found.

Conclusions: THA is an effective and safe option for hip tuberculosis. The essentials for good outcome include early diagnosis, regular perioperative anti-tubercular chemotherapy, radical debridement of inflamed tissue and necrotic bone, staged-operation if necessary.

Keywords: Total hip arthroplasty; hip tuberculosis; anti-tubercular chemotherapy; reactivation

Submitted Nov 12, 2020. Accepted for publication Jan 22, 2021.

doi: 10.21037/apm-20-2544

View this article at: http://dx.doi.org/10.21037/apm-20-2544

\section{Introduction}

Tuberculosis (TB) is a significant global medical problem. It is one of the top 10 causes of mortality worldwide and the chief cause of death from a single infectious pathogen. Globally, an estimated 10 million people (range, 9.0-11.1 million) contracted TB in 2018, with an estimated 1.2 million (range, 1.1-1.3 million) TB deaths among HIV-negative people (1). TB of the hip accounts for approximately $10-15 \%$ of osteoarthritic TB $(2,3)$, and is second only to the spine for tuberculous involvement sites (4). With a timely diagnosis and regular treatment using first-line antibiotics, most TB patients can be cured. However, without early diagnosis, advanced stage TB can lead to joint destruction, and management of the disease can become technically demanding (5-8).

Besides the pre- and post-operative anti-tubercular therapy (ATT), the surgical options for advanced tubercular hip include resection arthroplasty, arthrodesis, and total hip 
Table 1 Demographic characteristics of seven hip tuberculosis patients

\begin{tabular}{|c|c|c|c|c|c|c|c|}
\hline Case & Gender & $\begin{array}{c}\text { Age (at } \\
\text { diagnosis) }\end{array}$ & Type & Co-morbidities & Pre-op ESR & Pre-op CRP & $\begin{array}{l}\text { Mixed- } \\
\text { infection }\end{array}$ \\
\hline 1 & Male & 57 & Active & $\begin{array}{c}\text { Sinus tract/obsolete } \\
\text { pulmonary tuberculosis/ } \\
\text { pneumothorax }\end{array}$ & 116 & 136.92 & S. aureus \\
\hline 2 & Female & 45 & Quiescence for 2 years & Lumbar tuberculosis & 25 & 5.69 & Negative \\
\hline 4 & Male & 26 & Active & Arrhythmia & 221 & 65.77 & Negative \\
\hline 5 & Male & 23 & Quiescence for 7 years & None & 16 & 3.67 & Negative \\
\hline 6 & Male & 47 & Quiescence for 12 years & Hypertension & 5 & 5.41 & Negative \\
\hline 7 & Female & 20 & Quiescence for 1 year & None & 9 & 7.83 & Negative \\
\hline
\end{tabular}

ESR, erythrocyte sedimentation rate; CRP, C-reactive protein.

replacement (THR). Resection arthroplasty and arthrodesis can provide pain relief and infection control, and adversely abnormal gait, difficulty of conversion to THR. However, resection arthroplasty can result in instability and leg length discrepancy (9-11), and arthrodesis can lead to hip immobility, adjacent joint degeneration, lower back pain, and probable non-union (12).

The demands for quality of life among patients are increasing, especially since many patients are relatively young and have several decades of active life remaining. Thus, they require a painless, stable, and functional hip joint. However, THR for TB of the hip still involves many controversial issues related to infection reactivation, surgical timing, perioperative ATT regime, long-term survival of prosthesis, etc. The purpose of our research was to investigate the feasibility and outcome of different treatment options through a review of the clinical data of seven patients between November 2014 and September 2018. We hope that our study provides some insight into the clinical treatment of TB of the hip.

We present the following article in accordance with the AME Case Series reporting checklist (available at http:// dx.doi.org/10.21037/apm-20-2544).

\section{Methods}

Seven patients with TB of the hip were treated with total hip arthroplasty (THA) in the Orthopaedic Department of Guizhou Provincial People's Hospital from November 2014 to September 2018. Of these, five were men and two were women, with a mean age of 34.3 years (range, 20-75 years).
Three patients were in the active phase and four patients were in quiescence. Two patients suffered right hip infection, while the remaining five patients had left hip infection. One patient was accompanied with obsolete pulmonary TB and pneumothorax, and one patient had lumbar TB. One patient had sinus tract drainage and tested positive for mixed infection of Staphylococcus aureus, while another patient had three healed sinus tracts (Table 1).

All patients received anti-tubercular chemotherapy [isoniazid $(300 \mathrm{mg} / \mathrm{d})$, rifampicin $(450 \mathrm{mg} / \mathrm{d})$, ethambutol $(750 \mathrm{mg} / \mathrm{d})$, and pyrazinamide $(750 \mathrm{mg} / \mathrm{d})]$ preoperatively for an average of 3.4 weeks (range, 2-6 weeks), and postoperatively for an average of 16.7 months (range, 1218 months). Inflammatory indicators, including erythrocyte sedimentation rate (ESR) and C-reactive protein (CRP), had decreased significantly before surgery in all active patients (Table 2).

The patient with sinus tract and mixed infection received three-stage surgery. The first stage surgery involved radical debridement, sinus tract resection, and implantation of a vancomycin-loaded cement spacer, while the second stage surgery involved cement spacer replacement and was conducted 2 months after the first surgery due to spacer breakage resulting from poor compliance. Final implantation of the hip prosthesis was completed 6 months later (Figure 1). The remaining six patients received one-stage surgery involving thorough debridement and prosthesis implantation. All patients were allowed weightbearing 1 day after THA (Figure 2). All procedures performed in this study involving human participants were in accordance with the Declaration of Helsinki (as revised 
Table 2 Treatments and results of seven hip tuberculosis patients

\begin{tabular}{|c|c|c|c|c|c|c|c|c|}
\hline \multicolumn{2}{|c|}{ ATT period } & Surgery & $\begin{array}{l}\text { Follow- } \\
\text { up (m) }\end{array}$ & Reactivation & \multicolumn{2}{|c|}{ Harris score } & $\begin{array}{c}\text { Last-FU } \\
\text { ESR }\end{array}$ & $\begin{array}{c}\text { Last-FU } \\
\text { CRP }\end{array}$ \\
\hline 6HRZE & 6HRZE12HRE & $\begin{array}{l}\text { Sinus resection, } \\
\text { debridement, spacer/ } \\
\text { debridement, spacer/ } \\
\text { debridement, THA }\end{array}$ & 71 & Negative & 15 & 80 & 8 & 2.57 \\
\hline 6HRZE & 3HRZE15HRE & Debridement, THA & 34 & Negative & 31 & 87 & 10 & 1.05 \\
\hline 4HRZE & 3HRZE15HRE & Debridement, THA & 44 & Negative & 38 & 85 & 2 & 2.1 \\
\hline 2HRZE & 3HRZE9HRE & Debridement, THA & 51 & Negative & 42 & 91 & 15 & 3.46 \\
\hline 2HRZE & 3HRZE12HRE & Debridement, THA & 37 & Negative & 49 & 95 & 7 & 4.33 \\
\hline
\end{tabular}

ATT, anti-tubercular therapy; FU, follow-up; ESR, erythrocyte sedimentation rate; CRP, C-reactive protein; THA, total hip arthroplasty. HRZE: $H$, isoniazid; $R$, rifampicin; $Z$, pyrazinamide; $E$, ethambutol. HRE: $H$, isoniazid; $R$, rifampicin; $E$, ethambutol.

in 2013). The study was approved by institutional ethics committee of Guizhou provincial people's hospital (No.EC20201026-1017) and informed consent was taken from all the patients.

\section{Results}

The mean follow-up time was 41.6 months (range, 25-71 months), and no reactivation was detected. The average Harris score increased from 40.0 (range, 15-58) preoperatively to 89.4 (range, 8-98) at the final follow-up. The ESR of the three active TB of the hip cases decreased from $143.7 \mathrm{~mm} / \mathrm{L}$ (range, $94-221 \mathrm{~mm} / \mathrm{L}$ ) at the time of diagnosis to $6.7 \mathrm{~mm} / \mathrm{L}$ (range, $2-10 \mathrm{~mm} / \mathrm{L}$ ) at the final follow-up. The CRP of the three active TB of the hip cases decreased from $80.01 \mathrm{mg} / \mathrm{L}$ (range, 37.34-136.92 mg/L) at the time of diagnosis to $1.91 \mathrm{mg} / \mathrm{L}$ (range, $1.05-2.57 \mathrm{mg} / \mathrm{L}$ ) at the final follow-up. The ESR and CRP of all patients had returned to a normal level at the final follow-up. No prosthesis dislocation, loosening, or neurovascular injury was observed (Table 2).

\section{Discussion}

Staged surgery is the gold standard treatment for severe infectious destruction of the skeletal and joint systems. First stage surgery involves radical debridement and curettage of inflammatory and necrotic tissue, with or without implantation of an antibiotic-loaded cement spacer.
Second stage surgery is carried out after the infection is under control, and involves once more debridement and implantation of the metal prosthesis. The necessity of staged surgery results from adherence to the metal surface as well as the biofilm-forming characteristics of common bacteria. Bacteria coated with biofilm have strong resistance to antibiotics and host immune attack, which can ultimately lead to serious surgical failure (13). Some authors have suggested that staged surgery with anti-TB chemotherapy could minimize the reactivation of TB. Li et al. (6) held the view that it is difficult to achieve thorough debridement of advanced hip infection diffused to the thigh or pelvis, and recommended two-staged surgery.

In contrast to common pyogenic pathogens, TB bacilli have unique biological characteristics, including that they are slow-growing, they do not adhere to metal surfaces, and have scarce biofilm-formation (13-15). Encouraged by the success of one-staged surgery with metal implantation for active spinal TB $(16,17)$, an increasing number of surgeons have applied one-staged surgery for the treatment of TB of the hip, with satisfactory results $(8,15,18,19)$.

However, in addition to the anti-TB chemotherapy, the quiescence before THA reported by different authors varied from immediately to 20 years $(8,18-21)$. There have also been some cases of reactivation reported after a very long time of quiescence. Johnson et al. (22) encountered two patients who had TB of the hip in childhood and had no manifestation of infection for 42 and 37 years, respectively. Reactivation of TB emerged 1 year after THA 

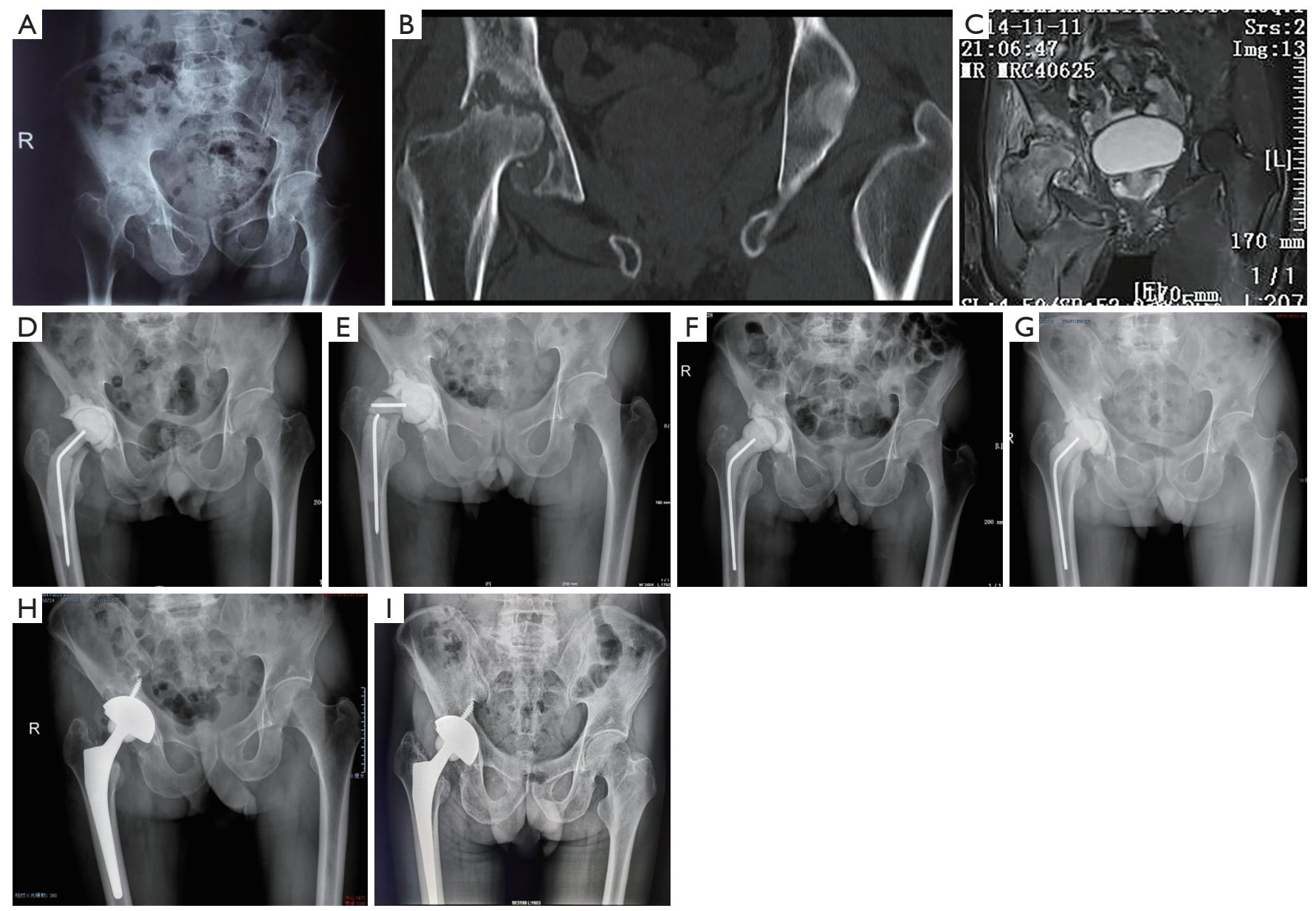

Figure 1 A 57 years old man was diagnosed active hip tuberculosis with sinus tract drainage. Preoperative X-ray (A), CT scan (B) and MRI (C) showed joint destruction and cold abscess. (D) Postoperative radiograph of first-stage surgery (sinus tract resection, radical debridement and implantation of vancomycin-loaded cement spacer). (E) Two months postoperatively, spacer breakage occurred due to poor compliance. (F) The patient received second-stage surgery (debridement and replacement of cement spacer). (G,H) Eight months postoperatively, the final metal prosthesis was implanted. (I) Seventy months postoperatively, the final follow-up radiograph showed good position and growth-up of prosthesis.

for two ankylosing hips. These two patients were treated in childhood with conservative immobilization only (i.e., without anti-TB chemotherapy). In our retrospective cases, the quiescence before THA was not taken into consideration when deciding the surgical timing. Also, the standard firstline anti-TB chemotherapy, including isoniazid, rifampicin, pyrazinamide, and ethambutol, was applied for every patient for between 2 and 6 weeks preoperatively and between 12 and 18 months postoperatively.

Many authors hold the opinion that sinus tract drainage is contraindicated in one-staged surgery for treating TB of the hip $(6,15,23)$. Sinus tract drainage is often accompanied by mixed infection with other common pyogenic pathogens including multi-drug resistant super-bacteria. Li et al. (6) reported a series of four $\mathrm{TB}$ of the hip cases with sinus tract; they selected two-staged surgery with regular anti-TB chemotherapy, and ultimately achieved a satisfactory result. In our study, we chose three-staged treatment for cases with sinus tract, with anti-TB chemotherapy and intravenous administration of sensitive antibiotics.

\section{Conclusions}

THA is an effective and safe option for TB of the hip. 

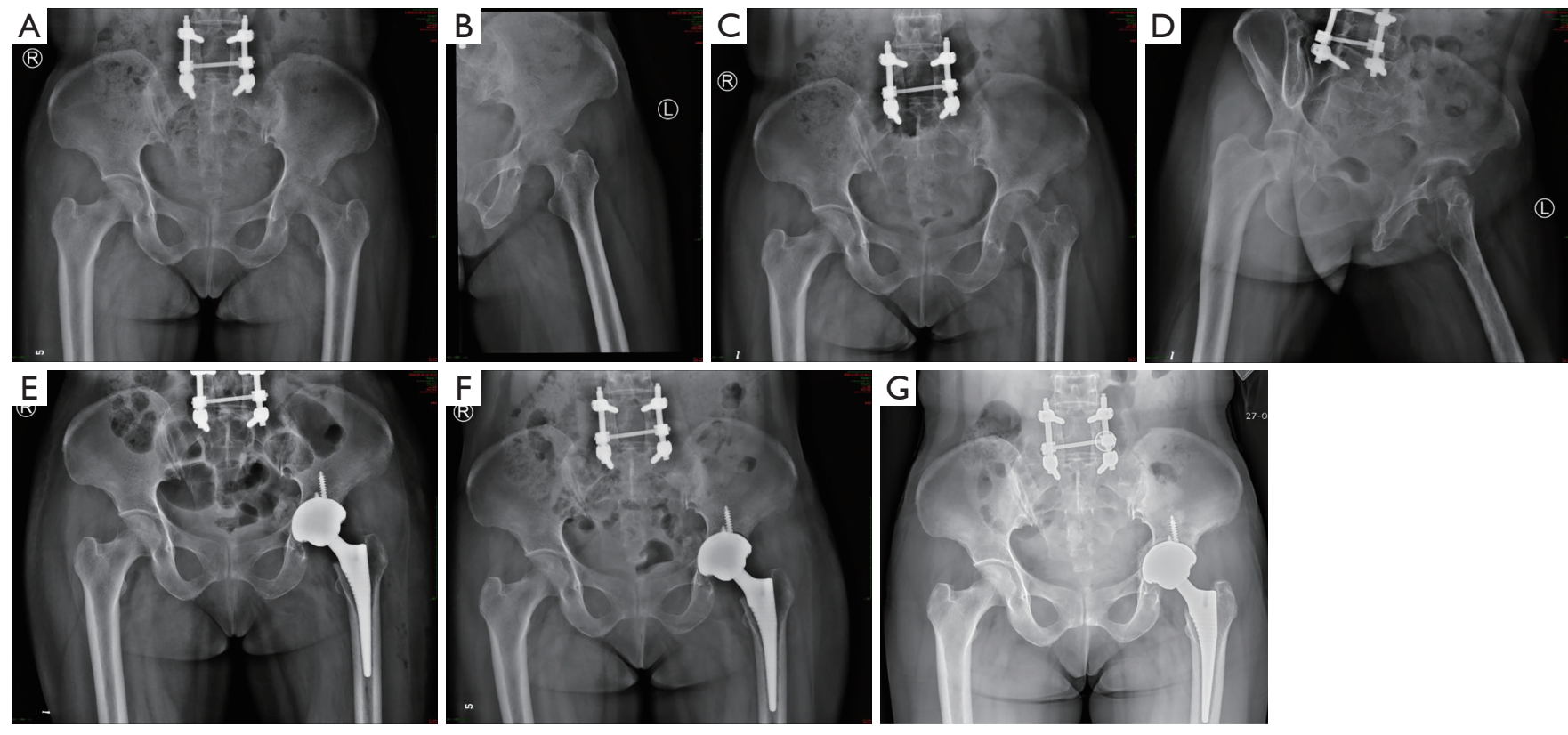

Figure 2 A 45-year-old woman suffered left hip tuberculosis. (A,B) The X-ray showed affected left hip. (C,D) After anti-tubercular chemotherapy for six months. (E) The patient received total hip arthroplasty. (F) The follow-up X-ray two months postoperatively. (G) The follow-up X-ray 26 months postoperatively.

The essentials for good surgical outcomes include early diagnosis, regular perioperative anti-TB chemotherapy, radical debridement of inflamed tissue and necrotic bone, as well as staged-surgery if necessary.

\section{Acknowledgments}

Funding: (I) National Natural Science Foundation of China (No. 81960401); (II) Guizhou Province Science and Technology Project ([2019]1429).

\section{Footnote}

Reporting Checklist: The authors have completed the AME Case Series reporting checklist. Available at http://dx.doi. org/10.21037/apm-20-2544

Data Sharing Statement: Available at http://dx.doi. org/10.21037/apm-20-2544

Conflicts of Interest: All authors have completed the ICMJE uniform disclosure form (available at http://dx.doi. org/10.21037/apm-20-2544). The authors have no conflicts of interest to declare.
Etbical Statement: The authors are accountable for all aspects of the work in ensuring that questions related to the accuracy or integrity of any part of the work are appropriately investigated and resolved. All procedures performed in this study involving human participants were in accordance with the Declaration of Helsinki (as revised in 2013). The study was approved by institutional ethics committee of Guizhou provincial people's hospital (No.EC20201026-1017) and informed consent was taken from all the patients.

Open Access Statement: This is an Open Access article distributed in accordance with the Creative Commons Attribution-NonCommercial-NoDerivs 4.0 International License (CC BY-NC-ND 4.0), which permits the noncommercial replication and distribution of the article with the strict proviso that no changes or edits are made and the original work is properly cited (including links to both the formal publication through the relevant DOI and the license). See: https://creativecommons.org/licenses/by-nc-nd/4.0/.

\section{References}

1. World Health Organization, Global tuberculosis report 
2019,2019:1.

2. Babhulkar S, Pande S. Tuberculosis of the hip. Clin Orthop Relat Res 2002;398:93-9.

3. Tuli SM. Tuberculosis of the Skeletal System: Bones, Joints, Spine and Bursal Sheaths. Jaypee Brothers Publishers, 2004.

4. Caparros AB, Sousa M, Ribera Zabalbeascoa J, et al. Total hip arthroplasty for tuberculous coxitis. Int Orthop 1999;23:348-50.

5. Tan SM. Total hip arthroplasty for surgical management of advanced tuberculous hip arthritis: case report. World J Orthop 2015;6:316.

6. Li L, Chou K, Deng J, et al. Two-stage total hip arthroplasty for patients with advanced active tuberculosis of the hip. J Orthop Surg Res 2016;11:38.

7. Kumar V, Garg B, Malhotra R. Total hip replacement for arthritis following tuberculosis of hip. World J Orthop 2015;6:636-40.

8. Wang Y, Wang J, Xu Z, et al. Total hip arthroplasty for active tuberculosis of the hip. Int Orthop 2010;34:1111-4.

9. Clegg J. The results of the pseudarthrosis after removal of an infected total hip prosthesis. J Bone Joint Surg Br 1977;59:298-301.

10. Tuli SM, Mukherjee SK. Excision arthroplasty for tuberculous and pyogenic arthritis of the hip. J Bone Joint Surg Br 1981;63-B:29-32.

11. Dallari D, Fini M, Carubbi C, et al. Total hip arthroplasty after excision arthroplasty: indications and limits. Hip Int 2011;21:436-40.

12. Lipscomb PR, McCaslin FE. Arthrodesis of the hip. J Bone Joint Surg 1961;43:923-34.

13. Stewart PS, Costerton JW. Antibiotic resistance of bacteria in biofilms. Lancet 2001;358:135-8.

14. Ha KY, Chung YG, Ryoo SJ. Adherence and biofilm formation of Staphylococcus epidermidis and

Cite this article as: Zhang J, Liang L, Yang B, Li S, Yang X, Li J, Sun L, Han W. Total hip arthroplasty for tuberculosis. Ann Palliat Med 2021;10(1):495-500. doi: 10.21037/apm-20-2544
Mycobacterium tuberculosis on various spinal implants. Spine (Phila Pa 1976) 2005;30:38-43.

15. Neogi DS, Yadav CS, Ashok K, et al. Total hip arthroplasty in patients with active tuberculosis of the hip with advanced arthritis. Clin Orthop Relat Res 2010;468:605-12.

16. Govender S. The outcome of allografts and anterior instrumentation in spinal tuberculosis. Clin Orthop Relat Res 2002;398:60-6.

17. Zhang J, Wu XL, Lu TS, et al. Application of one-stage posterior surgery via unilateral musculus sacrospinalis iliac flap approach in treatment of lumbosacral tuberculosis. Chinese Journal of Reparative and Reconstructive Surgery 2019;33:296-301.

18. Yoon TR, Rowe SM, Anwar IB, et al. Active tuberculosis of the hip treated with early total hip replacement-a report of 3 cases. Acta Orthop Scand 2001;72:419-21.

19. Yoon TR, Rowe SM, Santosa SB, et al. Immediate cementless total hip arthroplasty for the treatment of active tuberculosis. J Arthroplasty 2005;20:923-6.

20. Hardinge K, Williams D, Etienne A, et al. Conversion of fused hips to low friction arthroplasty. J Bone Joint Surg Br 1977;59-B:385-92.

21. Kim YH, Han DY, Park BM. Total hip arthroplasty for tuberculous coxarthrosis. J Bone Joint Surg Am 1987;69:718-27.

22. Johnson R, Barnes KL, Owen R. Reactivation of tuberculosis after total hip replacement. J Bone Joint Surg Br 1979; 61-B:148-50.

23. Oztürkmen Y, Karamehmeto M, Leblebici C, et al. Cementless total hip arthroplasty for the management of tuberculosis coxitis. Arch Orthop Trauma Surg 2010;130:197-203.

(English Language Editor: A. Kassem) 